\title{
Overview. Standing on the Threshold: Food Justice in India
}

\author{
Lawrence Haddad, C.P. Chandrasekhar and Biraj Swain
}

\begin{abstract}
This piece provides a summary of the articles detailing the recent fight for food justice in India. It begins by providing an overview of the state of food and nutrition in India and reflects on the experience to date of the role of the courts in promoting food justice. It goes on to describe some of the ongoing struggles to claim rights and justice, highlighting implementation, capacity, incentive and cultural barriers to realisation. Finally, this article focuses on the enduring and new challenges to attaining food security in India, strong food justice system or not.
\end{abstract}

\section{Introduction}

India stands on the threshold of potentially the largest step toward food justice the world has ever seen. 'Threshold' because the National Food Security Bill (NFSB) is working its way through parliament with a view to being passed during its current term period. 'Largest' because the Bill will cover approximately 70 per cent of all Indian households, easily the highest proportion of households covered by such a programme anywhere in the world. 'Justice' because the improved access to food has been catalysed, monitored and ordered by the courts, starting with the Supreme Court. 'Potential' because (a) having a Bill on the books is quite different from having it implemented, (b) the Bill is only as good as the programmes it has to work through, and (c) there are many threats to food security that are way beyond the Bill's remit climate change being the most significant. 'Step forward' because Indian food security and nutrition levels are not being swept up in the tide of gross domestic product per capita growth - they remain rooted to the seabed.

This special IDS Bulletin, co-constructed with Oxfam India, brings together the views and opinions of some of India's leading practitionerthinkers on these issues. We want these articles to infuse live food security debates in India. How, for example, to ensure the most marginalised are not excluded from India's major food and nutrition programmes? How to protect the land and mineral rights of the marginalised, the Scheduled Tribes (ST) and Scheduled Castes (SC)? How to improve farm productivity in a way that empowers women? How to make food and nutrition issues more newsworthy? How to assess government commitments to reducing hunger? How to address food price inflation and volatility? How to claim the agrarian agenda in Eastern India and prioritise rainfed agriculture for holistic gains in the national agricultural sector? How to stimulate agriculture in the context of a changing climate? And finally, how to ensure that India's claims to climate justice in the international arena are not undermined by domestic injustices?

We have organised the 14 articles into three sections. The first provides an overview of the state of food and nutrition in India and reflects on the experience to date of the role of the courts in promoting food justice. The second section describes some ongoing struggles to claim rights and justice, highlighting the implementation, capacity, incentives and cultural barriers to their realisation. The final section focuses on the enduring and new challenges to attaining food security in India, National Food Security Bill or not.

\section{Overview of food and nutrition in India}

We are fortunate to have as authors for this section the two Special Commissioners to the Supreme Court on the Right to Food N.C. Saxena and Harsh Mander. Saxena's article

IDS Bulletin Volume 43 Number S1 July 2012 @ 2012 The Authors. IDS Bulletin (c) 2012 Institute of Development Studies Published by Blackwell Publishing Ltd, 9600 Garsington Road, Oxford OX4 2DQ, UK and 350 Main Street, Malden, MA 02148, USA 
reminds us that the percentage of India's young children that are malnourished (using stunting or low height for age criteria) is higher than most sub-Saharan African countries, at 43 per cent. The latest multi-state survey ${ }^{1}$ from 2011 shows some modest declines in malnutrition in some states between 2005 and 2011 as measured by low weight for age (underweight), but it did not collect stunting data so we do not know what the trends are for the most important and stubborn nutrition indicator. The article reminds us of the decline in average calorie intake during the last 25 years in India and that the causes of this decline remain a puzzle. The article asks the question: will the NFSB be able to reduce hunger and malnutrition? The answer, Saxena reminds us, will in large part depend on non-legal factors, namely the effectiveness of India's flagship food and nutrition policies and programmes: agricultural development, Targeted Public Distribution System (TPDS), Integrated Child Development Services (ICDS) and the Mid Day Meal (MDM) Scheme.

He expertly summarises the state of play in these various policies and programmes and gives us his views on some of the newer policy debates. $\mathrm{He}$ argues for a renewed focus on smallholder agriculture (those with holdings of less than 4 hectares still constitute 90 per cent of farmers and about 60 per cent of farmed land,

Ramanjaneyulu, this IDS Bulletin), especially in the areas where poverty is the most stubborn and even growing. He notes that the NFSB will rely heavily on a rather leaky vessel, the TPDS. He urges civil society to become more active in exposing poor quality and outright fraud, and he points out that there are many TPDS

experiments ongoing in the various states, some successful, and all with lessons to share. The still controversial unique identity (UID) programme may help weed out duplicate programme eligibility cards, which is good, but would in his view not stop the determined ineligible individual from gaining access. On the use of cash transfers as a complement to or substitute for the TPDS, he is less optimistic, noting the strong financial infrastructure that would need to be in place, and he advocates evaluation of pilots.

For the ICDS programme, the main instrument to combat infant malnutrition, Saxena summarises the list of problems: not enough focus on children under two, too food focused, poor quality of service delivery, understaffed and unhygienic ICDS centres, poor outreach to homes, exclusion of minorities, weak oversight and accountability, and no impact studies. Finally, he notes that these policies and programmes will not reduce malnutrition on their own. Malnutrition reduction will need a comprehensive and strategic approach - attention to water and sanitation and health systems - and the governance reforms to make them responsive and accountable to the people they are aiming to serve.

If Saxena notes that civic and judicial activism on its own is insufficient to improve food security, Mander reminds us that in India it has been necessary to get some movement. If one believes that people are impoverished more by chance and the way the political economy is structured than by their individual attributes then the state has an obligation as a duty-bearer to help redress power imbalances. He takes us through the last ten years of experience in India whereby a combination of civic and judicial activism has helped elaborate an important socioeconomic right, and progressively made segments of it judiciable. Two Articles of the Indian Constitution are particularly vital: Article 21 'No person shall be deprived of his life or personal liberty except according to procedure established by law' and Article 47 'The State shall regard the raising of the level of nutrition and the standard of living of its people and the improvement of public health as among its primary duties'. Given that life is biologically impossible without food, these two Articles have helped underline the importance of food as a core right. The Supreme Court has done four key things in the past ten years to help this right be unpacked and implemented, it:

1 turned eight programmes into entitlements by mandating that State Governments could not withdraw from or abridge them,

2 appointed two Special Commissioners to independently monitor implementation and gaps,

3 ordered expansion of mode and content of these programmes, and

4 ordered them to be universalised.

On a case-by-case basis the Court has 'in effect "explicated" or unpacked the right in relation to each segment of people' (see Mander, this IDS Bulletin). It is fair to say that the tabling of legislation that promises food security to a 
substantial section of the population, even if not for all, would have been delayed by several years in the absence of this potent mix of civil and judicial intervention in securing the people's right to food. Future impact evaluations will tell us exactly how transformative they have been in terms of outcomes, but they have already been so in terms of voice.

\section{Hungry for justice}

The cluster of articles in this section of the IDS Bulletin shows how difficult it is to realise rights, giving examples for specific groups of individuals. The articles from Mamgain and Diwakar, and Swain and Kumaran, focus on who is excluded from major food and nutrition programmes, why, and what can be done about it. Shah writes on women's empowerment, and Padel gives us his views on Adivasi's land and mineral rights. The last two articles in this section ask more generally, what can be done to energise this striving for the realisation of rights by asking what the media can do (Guha Thakurta and Chaturvedi) and whether measuring government commitment to hunger reduction is feasible and desirable (te Lintelo).

Mamgain and Diwakar focus on the elimination of identity-based discrimination in food and nutrition programmes. The article first reminds us of the evidence that confirms the persistently higher level of under-nutrition faced by children from scheduled castes. It reviews the evidence on how ICDS and MDM programmes favour children and mothers who are not from SCs. It reviews the programme guidelines for delivering these government programmes and finds them lacking in sensitivity to the weak status of SC groups in decision-making and quality monitoring and finds them silent on how to address discrimination that is uncovered. Aware of the deep-rooted discrimination in Indian society and the challenges that arise in overcoming it, the article makes a number of recommendations on what the ICDS and MDM programmes can do differently: greater participation by marginalised groups like SC communities in service planning and delivery, ensuring quality and in promoting accountability more generally; training and sensitisation of service providers; and the revision of administrative guidelines to detect, address and monitor discrimination. It concludes by noting that 'These programmes cannot be expected to short-circuit deep-seated discrimination, but neither should they reinforce it.'
Swain and Kumaran also pick up on this theme: who do ICDS and the Public Distribution System (PDS) exclude and what can be done to change this? They usefully note the different types of exclusion: (1) Official exclusion, typically from committing too few resources (e.g. PDS resources are sufficient for 36 per cent of the population), (2) implementation flaws - making it too difficult to access resources, weak outreach, stigma, low quality of service, and (3) flawed policy - poor families who for one reason or another are just above the below the poverty line (BPL) cut-off or institutional discrimination of the sorts noted by Mamgain and Diwakar. Swain and Kumaran's view of the NFSB and exclusion is mixed. They argue that the persistence with a poverty cut-off simply perpetuates exclusion; they applaud the improved judiciability of exclusion due to implementation flaws, although they think the redress systems need to be tightened up. Finally, they point out that ICDS still excludes infants from access to non-Supplementary Nutrition Programme inputs (which are overly food focused) that are vital to prevent stunting. They acknowledge that 'Suggesting an agenda for change is a more difficult task than diagnosing forms of exclusion as it involves strategising in the context of the prevailing political economy. Therefore no quickfix takeaways are attempted here.' But they do make several key recommendations: (1) rights are claimed when they are desirable, so improve the quality of ICDS and PDS and make them universal, (2) make sure potential innovations such as biometrics, coupons, and cash transfers pass the acid test of empowering the poor, not just the bureaucrats, and (3) empower citizens to fix the ICDS and PDS as this can have wider benefits, and help fix the overall food system.

Shah lays out the priority changes needed to strengthen women's role as producers, processors and providers of food and nutrition. She notes that the 12th Five Year Plan is likely to emphasise increasing productivity in rainfed areas, and that this will rely even more on female agricultural labour. She also argues that helping women farmers become more productive is not necessarily an empowering process. It is not just a matter of women having more decision-making power within the current system, they need more power to change the system. As well as needing changes within agricultural programmes, agricultural research and technology, land and water rights, changes are needed so that macro 
policies value women's work across multiple domains. If women's work is only valorised through the market, their true contributions will be undervalued, work burdens will be underestimated, and trade-offs between activities will be miscalculated. Achieving all of this means working against entrenched sociocultural and legal constraints. 'This requires mobilisation, consolidation and handholding of the right kind of forces working within communities and groups of people committed to work toward the common goal.' A prominent role is foreseen for civil society organisations in anchoring such a process, even if facilitated by policy reforms.

Padel's article poses the question, how to ensure Adivasi's land, forest and mineral rights? This is one of those groups for whom rights have to be unpacked and implemented in a tailored way. Adivasis are a large group of individuals who are indigenous to India. Scheduled Tribes, with whom they share an overlap, number about 8 per cent of the population. Adivasis tend to reside in resourcerich environments (with great biodiversity) and have managed the environment well.

Displacement of these people, often in the name of food security and development has undermined their own food security. Such practices resulting in a marketisation of food and other material needs have been called cultural genocide, because as the Adivasis say, 'We can't eat money'. Padel asks why India's vaunted environmental and human rights legislation cannot protect the Adivasi? Padel argues it is because of poor implementation and contradictions between and even within laws. For example:

Like the Food Security Bill, a new Land Acquisition and Rehabilitation and Resettlement Bill, presently under parliamentary consideration, has been the focus of considerable lobbying by various factions. There has been pressure for some time to replace the notorious Land Acquisition Act of 1894, and coupling this with R\&R seems logical. The devil is in the detail however, and it has become clear that the need to give communities the right to veto land acquisition conflicts with accelerating demands for land 'for public purpose' by big corporations. For example, insistence on communities' Free Prior Informed Consent (FPIC) before their land is acquired continues to be debated. It is all too evident that Environmental Impact Assessments have often been full of false and biased data, while Public Hearings, required under the Environment Protection Act, are regularly manipulated, and falsely reported as 'Consent', even when entire communities have spoken out against a project. A moratorium on new land acquisition is required until a way of calculating and compensating social, economic and environmental costs is in place.

Padel concludes by arguing that the Rule of Law needed in tribal areas includes an enhanced public scrutiny of how natural resources are allocated to mining companies, and a far stronger regulation of mines and metal factories, with proper safeguards for affected communities.

The Supreme Court has stimulated civic and judicial activism. But has the media been a passenger or a driver of this energy? Guha Thakurta and Chaturvedi pick up this theme and ask how food and nutrition justice can be more newsworthy. Rigorous studies of the priorities given to these issues by newspapers are few and far between. The article reports on one such study by Joseph, a media scholar and independent journalist based in Bangalore. She scoured six English dailies published from Bangalore (four of them national) over the ten days leading up to 26 January 2006. She found that the most common references to food were in restaurant reviews and promotions, reports on food festivals and events such as a lunch at a fivestar hotel to promote vegetarianism, news about the launch of a book on cooking, advice on diet and nutrition, and research findings relating to food and health and recipes. What to do to change this? The main conclusion is that advocates need to understand the media better they are not going to change it. The rules of journalism are enduring and not open to exceptions. The five main news determinants are timeliness, prominence (importance), proximity (locality), consequence, and human interest. The food security advocates need to work with this framework. The balance is not easy to strike. Too scientific and it is too complicated for the reader. Too social and it becomes a silent issue. Too political and only floods and droughts are reported on, not the gnawing hunger that hollows out people, communities and entire populations. Advocates need to understand how the media works. They need to simplify 
messages, to tailor them to different reader segments, and also to form long-term working relationships with journalists. The new media, such as blogs, Twitter and Facebook, are highlighted as a challenge and an opportunity for speaking more directly to opinion formers.

Te Lintelo's article reports on an attempt to measure the political commitment to reduce hunger. The rationale is that hunger outcomes can be the result of many forces beyond the control of government. Outcomes should be measured, but we should also measure things the government can control: spending, policies, legislation, and rights. The article picks up on Mander's point about new resource allocations being one indicator of the success of the courts. But Mander's article, like the other articles in this section, also points out the vast gap between rhetoric and reality on rights. But indices do matter. Guha Thakurta and Chaturvedi present a detailed example of how considerable press interest around the Global Hunger Index was localised for India. Even more important than localising a story on an index, is the localising of the process of collection of the index. In this way te Lintelo hypothesises that the index can be even more powerful in facilitating the process of holding government to account on the strength of its efforts to reduce hunger.

\section{Maintaining food justice gains}

The NFSB and other legal and judicial mechanisms will no doubt strengthen food security outcomes in India. But gains need to be maintained. And there are plenty of stresses and strains that can erode gains. Food price rises, food price volatility and climate change are the ones focused on by the articles in the last section of this IDS Bulletin, with suggestions as to how to combat these stresses.

Chandrasekhar unpacks the nature and causes of food price levels and volatility. He notes that from a very low level in the late 1990s and early 2000 s, food price inflation increased steadily from 2003 to a peak in 2007, and then after a dip, rose to an even higher peak in 2009-10. He cites a number of triggers: basic supply (poor agricultural performance; importing of food price inflation) and demand (stronger economic growth after 2003), as well as new forms of speculation in India's growing commodities markets and increases in the administered price of food distributed through the PDS. He argues that the gainers are the large landholders (who can more easily hold stocks and time sales) and traders. The losers are poor consumers, already experiencing declining levels of calorie intake (see also Saxena, this IDS Bulletin) and spending large percentages of their income on food, especially those reliant on income sources that are not inflation linked. Chandrasekhar highlights food price levels as a greater threat to food security than volatility: 'A substantial part of this crisis is driven by the increasing levels of food prices, and to a lesser extent, increases in food price volatility. The Government of India needs to be much more focused on doing whatever it can to lower the price of food and stabilise it, especially for the benefit of the poorest in society.'

Swaminathan and Vepa's article explores similar territory, but from a more international perspective: what role can India play in preventing food price volatility? Many of the causes of volatility they analyse are similar to Chandrasekhar's: the widening demand-supply gap due to higher consumption of animal products and speculative trade in futures markets, and unfavourable weather conditions, possibly linked to climate change. But they also highlight the diversion of prime farmland for biofuels and real estate and increases in energy prices and other input costs. They highlight a range of policy responses covering the need to improve domestic food supply, improve the weak management of grain reserves and make the PDS more responsive to fluctuations in price and supply.

The article makes some interesting points about India's role in the region and beyond. Because of its size, India can: serve as an incubator of experiences and learning for others especially in agricultural technology and it can affect regional and even world prices through its level of exports and imports (trade management is key, not panic bans). This latter reason means that completion of the Doha trade round is vital to establish rulebased trade (but all nations need to abide by the rules). Finally the article points out that agriculture needs to adapt to climate change if the modest yield growth between 1990-2000 and 2000-10 is to be accelerated or even maintained.

In his article, Ramakumar analyses some of the large-scale investments in agriculture that India 
needs to make. He notes that public gross fixed capital formation (GFCF) in agriculture as a percentage of agricultural GDP has only been higher than 4 per cent once in the past 50 years (in 1978-79); although as a share of all government expenditure it has increased from approximately 3.5 per cent (2003-04) to approx. 5.5 per cent (2009-10). The article argues that this level of investment is inadequate and recent increases have not been 'decisive' and 'a revival of India's agricultural growth requires a far greater thrust to public spending'. Key areas of public investment to be increased are large and medium irrigation projects, agricultural research, and agricultural extension (which are growing at slower rates than in the 1970s and 1980s).

In their article, Acharya and Das highlight the neglect that dryland agriculture has suffered and the regressive practise of linking most agriculture support to irrigated land, which has been prevalent for many decades in India. They make a case for the Union Government to redesign the policy framework and provide the necessary budgetary support for agricultural activities in dryland/rainfed areas in the Eastern region states, especially as these are also the states with high concentrations of poverty. Rainfed agriculture provides a wide range of livelihood opportunities to millions of livestockdependent households, populations living in hilly and difficult terrains, forest dwellers and so on. Hence, there is an acute need to address some of the core concerns of such agricultural practices. They conclude with the crucial need for stepping up significantly the budgetary support for agriculture and allied sectors in the country and according much higher priority to rainfed agriculture within overall budgetary expenditure on the agriculture sector.

Ramanjaneyulu's article blends in the additional requirements of agriculture needing to adapt to climate change. He reminds us of the impacts of climate change on agriculture: (1) changes in the biology of plant and animal growth (including pest and disease shifts), (2) changes in the ecology of systems, and (3) the pressure on institutions to deal with climate-induced change, especially in rural areas. The article reminds us that agriculture is also a source of emissions (chemical fertilisers, burning crop residues, flooded paddies, large dams, livestock, and farm machinery). Despite the pressure to increase productivity while using fewer resources, public policy support to agriculture today favours high external input-based agriculture. Pilots of Sustainable Rice Intensification in Tripura, Orissa and Tamil Nadu and of Non-Pesticidal Management in Andhra Pradesh have been shown to be successful. Now the challenge is how these can be scaled up given the wide diversity of situations. This needs different approaches to capacity-building, learning, institutional systems and financial support.

Raghunandan's article on India's climate policy is the last in the set. He points out that India 'sits on a cleft stick' when it comes to climate policy. Its increasing power and influence makes it more difficult to play a backseat or spoiler role in climate negotiations, its growth means it is becoming a more significant emitter by the day, it has the capacity to develop greener growth, and yet it still needs pro-poor economic growth to drive down its massive poverty levels. An example of potential leadership is the modelling work done in India to allocate mitigation targets for all countries to keep global temperature rise within desired limits based on accumulated stocks of atmospheric carbon rather than annual flows. But the biggest climate disconnect might be between India's claims to climate justice in the international arena and domestic energy injustices. Building a strong domestic consensus on climate change brings legitimacy in international fora, but also confers legitimacy domestically. If you want a voice among the more powerful nations, how can you avoid giving a voice to the less powerful Indian citizens? If you want the more powerful nations to bear their share, then what are tax revenues in India doing to improve the availability of public transport especially rail and other green infrastructure that generate jobs. Along with climate-proofing and adaptation programmes, these would build a powerful support base for climate action by India and boost India's negotiating strength in international fora. The article concludes by noting 'The circle of India's climate policy dilemma cannot be squared unless domestic equity is addressed specifically and directly.'

\section{Concluding note}

This IDS Bulletin is a contribution to the increasing discourse and energy around the food justice agenda. It recognises that solving food injustice is a 'here and now' issue. Food justice is 
best claimed by activist civil society, leveraging the law courts and the court of public opinion. Policymaking and programme implementation must be guided by, and codify, food rights.

Evidence must be called upon to help resolve

dilemmas and guide action. Complacency must

\section{Notes}

1 The Hungama dataset was collected by The Naandi Foundation and can be found at www.hungamaforchange.org. not be tolerated - rights that have been claimed can be eroded by trends and events, or even taken away by the courts. Above all, ordinary people must be at the heart of the debate about what food justice means, how to attain it, and how to sustain it. 